\title{
A COMBINATION OF E-LEARNING AND CADAVERIC WORKSHOPS IMPROVES CONFIDENCE IN PERFORMING SUPRAINGUINAL FASCIA-ILIACA BLOCKS
}

M. James, S. Prasad, J. Womack, A. Qureshi, D. Buckley, I. Walker. Royal Victoria Infirmary, Newcastle Upon Tyne

$\underline{\text { Background and Aims }}$

- Fascia-iliaca blockade for patients with fractured neck of femur (NOF), is a safe and effective alternative to opioid-based analgesic regimes, with reductions in opioid requirements, easier patient nursing, and improvements in morbidity ${ }^{1}$.

- Early nerve-catheter placement can provide long lasting, peri-operative analgesia.

- The ultrasound-guided supra-inguinal approach is safe, simple to learn, has higher rates of success than landmark techniques, and is far more likely to spread local anaesthetic to the lateral femoral cutaneous and obturator nerves than infra-inguinal approaches. Catheter placement using this approach is straightforward ${ }^{2}$.

- Consideration of regional techniques for fractured NOF is recommended by NICE ${ }^{3}$, however, providing sufficient educational opportunities from clinical experience alone has proven difficult in our institution.

- We aimed to develop a novel, comprehensive teaching approach to allow mastery of this technique.
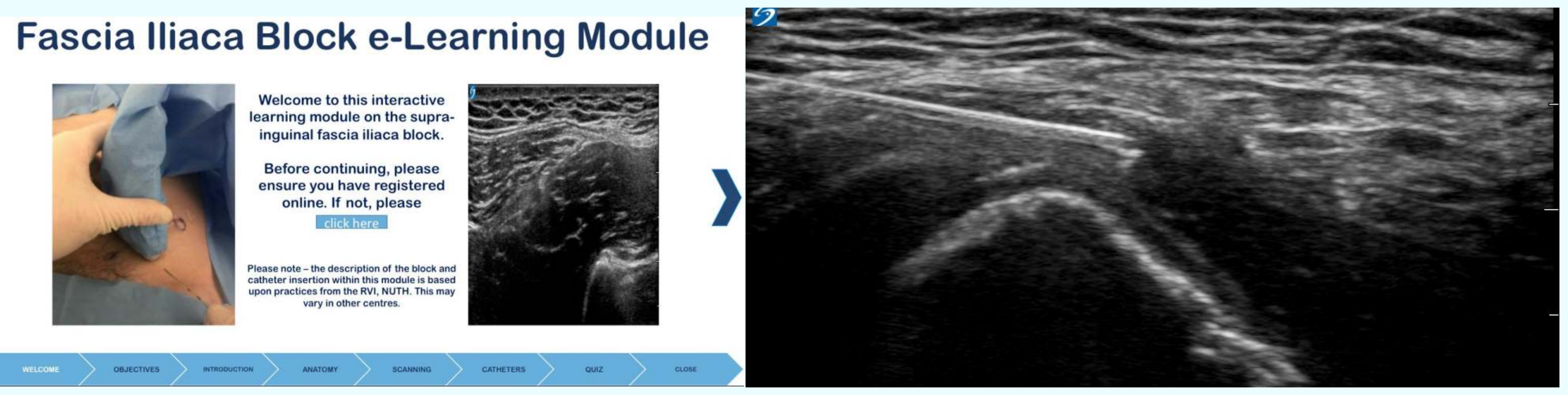

$\underline{\text { Methods }}$

There were two stages to our teaching:

- We developed an online e-learning package. This included background anatomical theory, complemented by interactive quiz material, and instructional videos.

- Closely supervised practical sessions using fresh-frozen cadavers, in small groups of 6 delegates.

- Each session lasted two hours, during which delegates could scan, needle, and inject, to maximise familiarity with the procedure. Catheter kits were also available to allow experimentation with their use.

Questionnaires were completed pre e-learning, post e-learning, and post course, regarding theoretical knowledge and confidence in performing this block. Delegates included a mix of trainees and consultants from anaesthetics and A+E.

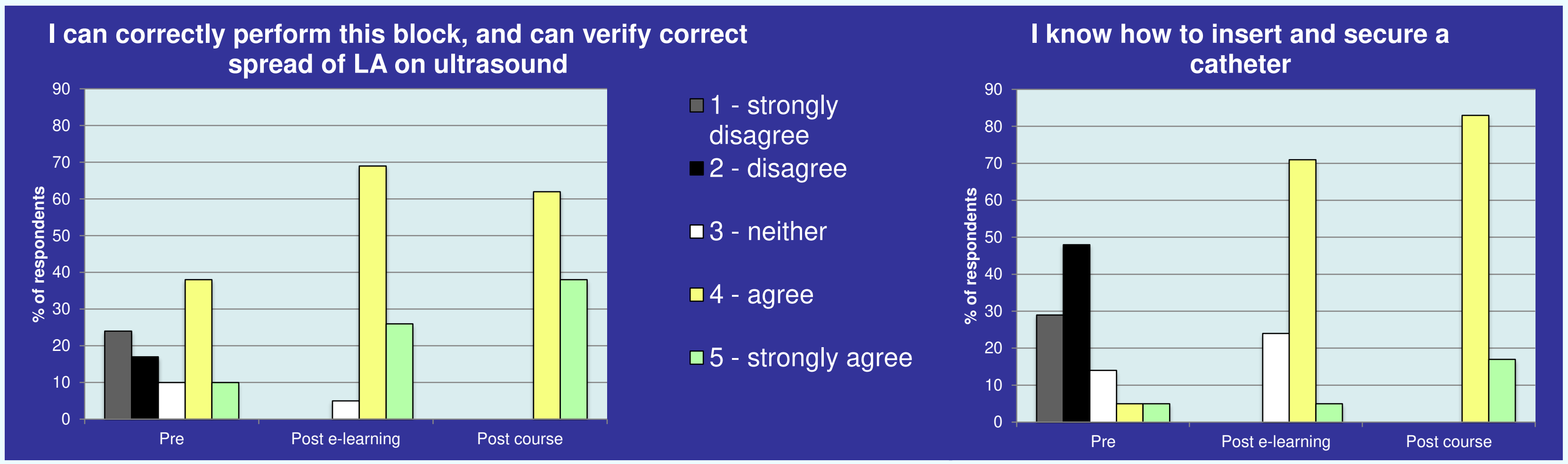

$\underline{\text { Results }}$

- 29 people completed the course and questionnaires.

- There was a statistically significant, stepwise improvement in the confidence of delegates regarding performing an ultrasound-guided suprainguinal fascia-iliaca block over the three questionnaires; from $48 \%$, to $95 \%$, to $100 \%$.

- Confidence inserting nerve catheters increased from $10 \%$, to $76 \%$, to $100 \%$.

Conclusions

- Self-assessed confidence at performing these techniques is improved significantly for this cohort using this novel teaching approach.

- A well prepared teaching package can be utilised when clinical exposure does not allow regular exposure to a certain regional technique.

- This teaching may translate to increased rates of use of these regional techniques for the frail population suffering from fractured NOF.

References:

1. Callear J, Shah K. Analgesia in hip fractures. Do fascia-iliaca blocks make any difference? BMJ open quality 2016;5:u210130.w4147

2. Dolan J, Williams A, Murney E, et al. Ultrasound guided fascia iliaca block: a comparison with the loss of resistance technique. Reg Anaesth Pain Med 2008;33(6):526-31

3. https://www.nice.org.uk/guidance/cg124 